\title{
Setor Educação e Sua Importância Econômica Para o Paraná
}

Education sector and its economic importance to Parana

\author{
Mari Aparecida dos Santos \\ Antonio Carlos Moretto \\ Rossana Lott Rodrigues \\ Ricardo Kureski
}

\section{Resumo}

Com enfoque no curto prazo como objetivo, esta pesquisa dimensionou a importância econômica do setor Educação Pública e Mercantil, no Paraná, em 2006, com relação à geração de emprego e renda, decompostos de acordo com o perfil escolar dos empregados. Por meio da análise insumoproduto em conjunto com informações contidas na Matriz Regional do Paraná de 2006 e na Pesquisa Nacional por Amostra de Domicílio (PNAD), o estudo evidencia os seguintes resultados: i) do total de pessoas ocupadas no Paraná em 2006, 5,6 milhões, 79,4\%, dividiam-se entre os que passaram pelos ensinos Fundamental e Médio; ii) a média salarial do grupo de trabalhadores com escolaridade equivalente a Pós-graduação foi $240 \%$ maior do que o salário médio dos trabalhadores do ensino Médio; iii) a geração de emprego e de renda mostrou a pujança econômica do setor, pois a Educação Mercantil e Pública, juntas, gerariam $8,5 \%$ do total de empregos e $9,7 \%$ do total da renda no Paraná.

Palavras-chave: Educação. Crescimento econômico. Insumo-produto.

\begin{abstract}
Focusing on the short run, as the objective, this research scaled the economic importance of the Public and Commercial Education like sectors, in Parana, in 2006, regarding the employment and income creation, broken down according to employees school profile. Through the input-output analysis together with the information contained in Regional Matrix of Parana in 2006 and in National Household Sample Survey (NHSS), the study showed the results: i) the total of employed people in Paraná in 2006, 5.6 million, $79.4 \%$, were divided between those who went through primary and secondary school; ii) the average wage of the workers group with education equivalent to Masters was $240 \%$ higher than the average wage of workers in the Middle school; iii) creation of employment and income showed the importance in the sector, Public and Commercial Education, together, would generate $8.5 \%$ of total employment and $9.7 \%$ of total income in Parana.
\end{abstract}

Key words: Education. Economic growth. Input-output.

\section{Introdução}

A educação como processo de desenvolvimento da capacidade física, intelectual e moral do indivíduo e, por conseguinte, da sociedade, age em longo prazo diante da certeza de que visa ao alcance de uma melhor integração do indivíduo. Enquanto que a educação como setor produtivo contribui direta e indiretamente com diversos setores da economia em curto prazo, por abranger grandes organizações que interagem como demandantes de outros segmentos, os quais, também, atuam como demandantes de outros setores. A educação como força econômica setorial gera, assim, um volume de insumos e produção para atender às universidades, faculdades, escolas, pré-escolas e instituições afins que compõem o setor.

O Estado do Paraná destaca-se frente à maioria das unidades da federação com relação à situação educacional dos seus habitantes. A população paranaense encontra-se entre as mais escolarizadas da nação e faz do estado um sugestivo cenário para estudos do desencadeamento de impactos regionais. Nesse contexto, com foco no curto prazo, a presente pesquisa procura responder à seguinte questão: qual a dimensão do impacto do setor Educação sobre a economia do Paraná em $2006 ?$

A atual pesquisa objetiva determinar qual a posição do setor Educação, Pública e Mercantil frente aos demais setores no que se refere às ligações intersetoriais e à geração de emprego e renda, no Paraná, em 2006, por meio da análise insumo-produto em conjunto com informações contidas na Pesquisa Nacional por Amostra de Domicílio (PNAD). 
A pesquisa é composta por cinco seções, incluindo esta introdução. Na segunda seção será apresentada breve revisão de literatura a respeito da importância da educação sob aspectos sociais e econômicos. A terceira sintetizará os procedimentos metodológicos. Na quarta, serão apresentados os resultados e discussão. Por fim, na quinta seção estarão expostas as considerações finais.

\section{Revisão de Literatura}

No Brasil, uma discussão iniciada por Langoni (1976) - que coloca a educação como principal fator determinante da desigualdade de renda enquanto outros autores defendem que as desigualdades foram efeitos colaterais das políticas econômicas implantadas - desencadeou o interesse sobre as implicações da educação. Posteriormente, estudos realizados por Barros, Camargo e Mendonça (1997); Ramos e Mendonça (2005); Ferreira e Veloso (2005) passam a associar fatores educacionais às disparidades de renda, à pobreza, ao tamanho das famílias, às condições de vida, ao aumento da produtividade da mão de obra e oportunidades no mercado de trabalho, além de outras externalidades. Apesar da educação não ser uma panacéia ao crescimento econômico, inegável tomar como imprescindível um nível mínimo de escolarização da população para a viabilidade do crescimento econômico. São várias as situações observáveis de altas taxas de crescimento, em direção ao desenvolvimento econômico, em países que investiram na educação formal dos seus recursos humanos.

O processo educacional é amplamente importante em todos os seus estágios. Cada estágio ou nível escolar opera de forma focada com objetivos distintos considerando as diferentes faixas etárias. Portanto, se os benefícios individuais da educação aumentam com o avanço da escolaridade em contrapartida, quanto menor for o nível escolar de um indivíduo, mais restritas serão suas oportunidades ${ }^{1}$.

Como benefício individual, pode-se apontar a relação positiva entre escolaridade e renda - posto que, renda, nesta pesquisa, refere-se à remuneração do trabalho. Há verificações empíricas do aumento significativo da remuneração de indivíduos com alto nível escolar. Conforme Zaist, Nakabashi e Salvato (2010), em estudo realizado para o Paraná, com base no modelo de Heckman, conjuntamente com a base de dados da Pesquisa Nacional por Amostra de Domicílios (PNAD), a variável nível educacional é determinante na renda dos trabalhadores, de forma que o ensino superior é o que mais proporciona retorno ao indivíduo. Embora em menor intensidade, a educação básica deve ser considerada importante para qualquer decisão de alocação de gastos públicos por ser a essência educacional indispensável à educação continuada.

De fato, as relações entre renda e escolaridade são um consenso enfatizado por diversos autores, mas relações condizentes às externalidades geradas, seja pelo aumento da escolaridade, seja pela consequente elevação da renda, são dificilmente quantificadas. Apesar dessa dificuldade, nota-se a existência de efeitos benéficos à sociedade, pois a educação de um indivíduo tem implicações não somente sobre ele próprio, mas, também, sobre aqueles ao redor. Segundo Barros e Mendonça (1997), o efeito educação, além de melhorar a condição de vida dos indivíduos que se educam, tende a gerar uma série de externalidades sobre o bem-estar daqueles que os rodeiam, devido à convergência ao aumento da produtividade da mão de obra e, por conseguinte, da sua remuneração, da expectativa de vida, possibilidade da redução do tamanho da família e do grau de pobreza futuro.

De outro modo, autores como Hanushek e Woessmann (2008), discursaram sobre as implicações da educação que foram além dos benefícios individuais e sociais, e, portanto, consideraram-na como um dos pilares do crescimento econômico no longo prazo.

Com relação às implicações de curto prazo, essas podem ser atribuídas à educação como produto final de grandes organizações, com uma imensidão de fluxos intersetoriais. É a educação considerada com todo potencial de um setor econômico. A educação pode ser observada sob o âmbito setorial, como responsável pela organização de grandes instituições de ensino, tanto públicas quanto privadas. Desse modo, relaciona-se a educação como setor econômico que oferta serviços em favor da qualificação do fator trabalho, com implicações em longo prazo, e demanda uma série de produtos e serviços de outros setores que, por sua vez, geram impactos diversos no curto prazo ${ }^{2}$.

Para o curto prazo, Rolim e Kureski (2007) realizaram estudo pioneiro para verificar os impactos gerados pelas Instituições de Educação Superior (IES) do Paraná em 2004. O objetivo foi verificar a importância dessas IES nos locais onde estão inseridas, com a utilização da Matriz de Contabilidade Social do Estado do Paraná e da adaptação do modelo de equilíbrio geral desenvolvido pela Universidade de Monash, na Austrália. O multiplicador de renda estimado foi 2,34, o que significa que, para cada unidade monetária gasta em benefício das IES, o valor adicional de renda gerado seria de 1,34 unidades monetárias. O multiplicador de emprego no Estado do Paraná foi estimado em 
2,53 em virtude dos gastos dos três componentes de demanda vinculados às IES estaduais, com a geração de um total de 21.073 empregos, em 2004.

No âmbito internacional, encontram-se estudos que levaram em consideração impactos gerados no curto prazo pelo consumo do setor educacional. Como exemplo, tem-se o trabalho de Duch, García e Parellada (2008), em que são quantificados os impactos econômicos gerados pelo sistema universitário público espanhol, bem como os multiplicadores do Valor Adicionado Bruto (VAB) e emprego, no período entre 1998 e 2004. Verificou-se, neste estudo, que a demanda final universitária, em 2004, foi responsável pela criação de aproximados 118 mil novos empregos diretos e indiretos.

Portanto, os estudos apresentados nesta seção evidenciam a importância do setor educacional para o resto da economia no que tange à produção, renda e emprego. Certamente demais fatores condicionantes do crescimento devem ser considerados para que os impactos no curto prazo sejam sentidos, entretanto a educação tem se revelado como um fator essencial.

\section{Metodologia}

\section{Dados e seu Tratamento}

Para a realização da presente pesquisa, foi utilizada a matriz insumo-produto regional do Paraná para 2006, construída por Kureski (2006), por ser esse o ano da matriz mais recente para o Estado. Conjuntamente com a análise insumo-produto, fez-se uso das informações contidas na Pesquisa Nacional por Amostra de Domicílios (PNAD) do ano de 2006 (IBGE, 2006).

A matriz insumo-produto paranaense de 2006 possui, originalmente, 41 setores econômicos. Cumpre esclarecer que para atingir o objetivo do trabalho foi necessário desagregar o setor Administração Pública com a finalidade de obter o setor Educação Pública, de forma que, após a desagregação a matriz utilizada nesta pesquisa, passou a ter 42 setores $^{3}$.

A atual pesquisa se atém aos impactos causados no curto prazo pelo setor educação, Pública e Mercantil, além de considerar todas as externalidades relacionadas à educação relatadas na segunda seção. O setor educação engloba diversas instituições de ensino, de educação forma e profissional conforme a Comissão Nacional de Classificação (IBGE, 2010), por isso causa impacto através dos gastos promovidos para compra de insumos de outros setores da economia.

A Matriz traz dados referentes à ocupação dos setores econômicos, a qual foi desagregada por nível de escolaridade. O critério de classificação educacional adotado nesta pesquisa está em conformidade com o adotado no Brasil, conforme prevê a LDB de 1996, Lei n. 9.394/96 (BRASIL, 1996).

Visto isso, padronizou-se, nessa pesquisa, o grau mínimo determinado para completar cada nível escolar, agrupando os empregados como segue: Sem instrução - menos de um ano de escolaridade; Fundamental - 1 a 8 anos de estudo; Médio - 9 a 11 anos de estudo; Graduação -12 a 14 anos de estudo; Pós-graduação - 15 anos ou mais de escolaridade; e Indefinido, aqueles que, por impossibilidade de identificação do seu nível escolar, caracteriza o sétimo grupo. Quando pertinente, os dois agrupamentos denominados Graduação e Pós-graduação foram chamados de Ensino Superior.

Com a base de dados concluída, partiu-se para a análise insumo-produto.

\section{Geradores de Emprego e Renda}

Os multiplicadores simples, ou geradores, são instrumentos úteis para verificar os impactos sobre determinado sistema econômico resultante de choques nos elementos exógenos, em curto ou longo prazos. O emprego dos de tal instrumento permite verificar os efeitos de políticas públicas sobre a produção total da economia ou sobre outras variáveis como emprego, renda, impostos, salários, valor adicionado, etc.

Sempre que se objetiva medir o impacto total da variação na demanda final, sobre emprego e renda, são utilizados os multiplicadores simples de impacto, técnica desenvolvida por J. M. Keynes, que se baseou em um trabalho de R. S. Kahn (MIERNYK, 1975).

Qualquer que seja o tipo de análise e o prazo considerado, o modelo de insumo-produto para análise de impacto ou previsão baseia-se na forma geral $X=(I-A)^{-1} \cdot Y$, em que as variáveis foram definidas anteriormente (MILLER; BLAIR, 2009). Assim, a partir dos coeficientes diretos e da 
matriz inversa de Leontief, é possível estimar, para cada setor da economia, o quanto é gerado, direta e indiretamente, das variáveis citadas acima para cada unidade monetária produzida para a demanda final, a partir da Equação 1:

$$
G V_{j}=\sum_{i=1}^{n} b_{i j} v_{i}
$$

em que, $G V_{j}$ é o gerador que mede o impacto total, direto e indireto, sobre a variável em questão; $b_{i j}$ é o ij-ésimo elemento da matriz inversa de Leontief e $v_{i}$ é o coeficiente direto da variável em questão.

\section{Resultados e discussão}

\section{Perfil escolar}

A ocupação foi decomposta em sete grupos classificados de acordo com o nível de escolaridade da mão de obra. Nas tabelas a seguir foram destacados os vinte setores que sobressaíram.

A Tabela 1 detalha a disposição dos empregados, em 20 setores econômicos do Paraná com maior número de trabalhadores dos 42 analisados, em 2006, conforme o grau de instrução escolar da ocupação, medido por anos de estudo. Constatou-se que a ocupação total era composta por cerca de 5,6 milhões de pessoas, das quais 263 mil empregados, ou 4,7\%, não haviam completado um ano de estudo, 2.421 mil, 43,1\%, classificavam-se no ensino Fundamental, 2.039 mil, 36,3\%, enquadravamse no Médio, enquanto uma pequena parcela, 361 mil, 6,4\%, classificava-se na Graduação e 471 mil, $8,4 \%$ da ocupação, com estudo equivalente a Pós-Graduação. O restante, 61 mil empregados que, por sua vez, representavam $1,1 \%$ do total de empregados ocupados, não declararam o nível de escolaridade e por sua pequena representatividade perante a amostra, foram omitidos das análises.

Verifica-se, na Tabela 1, que os cinco setores com maior concentração de mão de obra foram: Comércio e Serviços de Manutenção e Reparação (31); Agricultura silv./expl.florl. (1); Outros Serviços (40), que abrange atividades como serviços de lavanderias, tinturarias, cabeleireiros, tratamentos de beleza, entidades recreativas, culturais e desportivas e os empregos domésticos; Construção Civil (30); e Extrativa Mineral (2). O total de trabalhadores nos cinco setores acima correspondeu a 57,5\% da ocupação total no Paraná.

Em 2006, o setor Comércio e serviço de manutenção e reparação (31) obteve grande representatividade no Valor Adicionado Bruto do Paraná relativamente aos demais setores. No referido ano, tal setor, intensivo em mão de obra alocou $20,4 \%$ do total de ocupados. A mão de obra predominante tinha o ensino médio, de modo que $52,2 \%$ dos trabalhadores enquadravam-se nesse perfil. Do restante, apenas, $1,5 \%$ da sua ocupação não tinham instrução escolar, 33\% possuíam o ensino fundamental, enquanto, $12,7 \%$ tinham doze ou mais anos de estudo.

O setor Agricultura silv./expl.florl. (1) destacou-se por seu potencial produtivo, visto que o Paraná é o maior produtor de grãos do Brasil - salientando-se a soja, milho e trigo. Para tanto, o setor (1) necessitou de abranger $13,6 \%$ da ocupação total no Paraná, em 2006. O setor mostrou que a maior parte da sua ocupação possuía baixa escolaridade: do total de pessoas com menos de um ano de escolaridade, $54 \%$ trabalhavam em atividades da Agricultura, silvicultura e exploração florestal, enquanto o restante dividia-se nos demais setores econômicos. Dos trabalhadores do setor, $85,4 \%$ tinham até oito anos de estudo, 12,8\% tinham ensino Médio e somente 1,35\% possuíam mais de 12 anos de estudo.

O setor Construção Civil (30) teve a mesma característica do setor (1), com relação ao perfil da mão de obra. Da ocupação no setor (30), 74,3\% apresentava níveis escolares abaixo de nove anos de estudo. Classificaram-se no ensino Médio $19,1 \%$ dos trabalhadores do setor. E, semelhantemente ao primeiro setor destacado, havia pequena parcela com estudo equivalente à Graduação e Pós, $1,6 \%$ e $3,1 \%$, respectivamente.

O setor Outros Serviços (40) apresentou a mesma característica dos setores destacados anteriormente, embora os trabalhadores estejam relativamente melhor distribuídos, com $68,1 \%$ de seu pessoal com até oito anos de estudo, 25,2\% com ensino Médio, 5,7\% enquadrando-se no ensino superior, 2,8\% com estudo equivalente à Graduação e 2,4\% com Pós-graduação (Tabela 1). 


\begin{tabular}{|c|c|c|c|c|c|c|}
\hline \multirow{3}{*}{ SETOR } & \multirow{3}{*}{$\begin{array}{l}\text { OCUPAÇÃO } \\
\text { TOTAL (UN.) }\end{array}$} & \multicolumn{5}{|c|}{ OCUPAÇÃO PERCENTUAL POR ANOS DE ESTUDO } \\
\hline & & \multirow{2}{*}{$\begin{array}{c}\text { SEM } \\
\text { INSTRUÇÃO }\end{array}$} & $\begin{array}{l}\text { FUNDA- } \\
\text { MENTAL }\end{array}$ & MEDIO & $\begin{array}{c}\text { GRADU- } \\
\text { AÇÃO }\end{array}$ & POS \\
\hline & & & $1 \mathrm{~A} 8$ & 9 A 11 & 12 A 14 & $15 \leq$ \\
\hline (31) Com. e Serv. de manut. & 1.147 .110 & 1,5 & 33,0 & 52,2 & 8,1 & 4,6 \\
\hline (1) Agricultura silv./expl.florl. & 766.421 & 18,5 & 66,8 & 12,8 & 1,0 & 0,3 \\
\hline (40) Outros serviços & 641.634 & 6,6 & 61,5 & 25,2 & 2,8 & 2,4 \\
\hline (30) Construção civil & 342.689 & 4,3 & 70,0 & 19,1 & 1,6 & 3,1 \\
\hline (2) Extrativa mineral & 332.856 & - & 42,3 & 42,3 & - & 15,4 \\
\hline (42) Administração Pública & 288.237 & 3,0 & 19,0 & 43,2 & 12,2 & 21,2 \\
\hline (37) Serviços às empresas & 257.813 & 1,7 & 25,3 & 44,7 & 14,6 & 13,0 \\
\hline (32) Transp., armaz. e correio & 253.805 & 2,1 & 46,4 & 40,5 & 5,1 & 3,7 \\
\hline (41) Educação Pública & 207.521 & 1,1 & 10,7 & 18,6 & 20,6 & 47,5 \\
\hline (36) Serviços de aloj. e alim. & 197.593 & 1,0 & 47,6 & 44,5 & 1,9 & 4,4 \\
\hline (5) Têxteis e Vestuário & 160.551 & 0,7 & 44,6 & 46,2 & 2,8 & 3,8 \\
\hline (4) Alimentos, bebidas e fumo & 135.739 & 2,8 & 38,3 & 43,2 & 5,9 & 7,4 \\
\hline (39) Saúde mercantil & 126.706 & 1,3 & 22,3 & 46,5 & 13,1 & 14,3 \\
\hline (33) Serviços de informação & 110.217 & - & 16,6 & 61,9 & 12,7 & 8,7 \\
\hline (28) Móveis e prod. das ind. div. & 91.077 & - & 55,5 & 38,4 & 3,1 & 1,0 \\
\hline (34) Interm. finan. e seguros & 74.718 & 2,8 & 8,8 & 29,4 & 19,1 & 39,2 \\
\hline (38) Educação Mercantil & 68.846 & 0,7 & 16,0 & 24,2 & 22,7 & 35,5 \\
\hline (6) Prod. de mad. exceto móv. & 54.156 & 5,3 & 52,8 & 34,3 & 2,3 & 3,0 \\
\hline (15) Prod. min. não-metálicos & 38.354 & 6,4 & 60,2 & 25,8 & 4,3 & 1,6 \\
\hline (35) Serviços imob. e aluguel & 33.567 & 3,2 & 50,8 & 36,3 & 2,7 & 5,3 \\
\hline Demais setores & 285.316 & 2,9 & 32,7 & 46,0 & 8,5 & 8,3 \\
\hline Total & 5.614 .927 & 4,7 & 43,1 & 36,3 & 6,4 & 8,4 \\
\hline
\end{tabular}

Tabela 1 - Distribuição da ocupação total por setor e percentual por grupo de anos de estudo, Paraná, 2006.

Fonte: Elaboração dos autores.

O setor que mais abriga trabalhadores com mais de quinze anos de estudo foi o Educação Pública (41) com, aproximadamente, $21 \%$ do total de pessoas desse grupo, percentual que representa 98,5 mil empregados, devido à característica própria desse segmento. Em seguida estão os setores Administração Pública (42), com 61,1 mil; Comércio e Serviço de manutenção (31), com 52.7 mil; Extrativa mineral (2), com 51, 2 mil; Serviços às empresas (37), com 33,5 mil; Intermediação financeira e seguros (34), com 29,2 mil; e Educação Mercantil (38) com 24,4 mil empregados pósgraduados, os quais, juntos, empregaram $74,6 \%$ do pessoal enquadrado na Pós-Graduação.

Com relação à distribuição dos salários de acordo com o perfil escolar do pessoal ocupado nos 42 setores no Paraná em 2006, verificou-se que a remuneração total foi de $R \$ 55,8$ bilhões de reais, rateados em 1,8\% voltado ao grupo de trabalhadores sem instrução escolar, $25 \%$ aos classificados no Fundamental, 34,3\% para os trabalhadores do ensino Médio, 11,3\% à parcela de trabalhadores com Graduação e $26,8 \%$, a maior parcela da remuneração total, para os indivíduos enquadrados na Pós-Graduação. A parcela de renda voltada ao grupo de empregados com nível escolar Indefinido representou apenas $0,7 \%$ do total (Tabela 2 ).

\begin{tabular}{|c|c|c|c|c|c|c|}
\hline \multirow{3}{*}{ SETOR } & \multirow{3}{*}{$\begin{array}{l}\text { TOTAL POR } \\
\text { SETOR }\left(^{*}\right)\end{array}$} & \multicolumn{5}{|c|}{ REMUNERAÇÃO PERCENTUAL POR ANOS DE ESTUDO } \\
\hline & & $\begin{array}{c}\text { SEM } \\
\text { SẼ }\end{array}$ & $\begin{array}{l}\text { FUNDA- } \\
\text { MENTAL }\end{array}$ & MEDIO & $\begin{array}{c}\text { GRADU- } \\
\text { AÇÃO }\end{array}$ & POS \\
\hline & & & $1 \mathrm{~A} 8$ & $9 \mathrm{~A} 11$ & 12 A 14 & $15 \leq$ \\
\hline (31) Com. e Serv. de manut. & $8.786,68$ & 0,9 & 27,3 & 49,9 & 9,9 & 11,6 \\
\hline (42) Administração Pública & $8.603,19$ & 0,9 & 10,1 & 29,0 & 9,9 & 49,4 \\
\hline (34) Interm. finan. e seguros & $3.338,47$ & 0,8 & 2,4 & 16,3 & 17,3 & 63,0 \\
\hline (41) Educação Pública & $3.081,98$ & 0,4 & 6,2 & 11,0 & 16,8 & 64,9 \\
\hline (40) Outros serviços & $3.048,60$ & 4,5 & 49,6 & 29,0 & 6,7 & 8,5 \\
\hline (32) Transp., armaz. e correio & $2.910,52$ & 1,7 & 43,6 & 36,8 & 6,6 & 9,6 \\
\hline (1) Agricultura silv./expl.florl. & $2.597,73$ & 12,7 & 67,9 & 15,8 & 1,4 & 1,7 \\
\hline (4) Alimentos, bebidas e fumo & $2.558,51$ & 1,5 & 26,3 & 42,4 & 6,4 & 21,8 \\
\hline (37) Serviços às empresas & $2.203,84$ & 0,8 & 16,8 & 38,4 & 18,5 & 25,1 \\
\hline (30) Construção Civil & $1.482,64$ & 3,5 & 59,7 & 25,2 & 3,6 & 6,8 \\
\hline (25) Fabricação de veíc. Autom. & $1.465,56$ & - & 3,2 & 48,0 & 15,7 & 33,0 \\
\hline (2) Extrativa mineral & $1.428,80$ & - & 33,2 & 37,7 & - & 29,0 \\
\hline (29) S.I.U.P. & $1.352,77$ & 1,5 & 12,0 & 35,7 & 17,4 & 32,3 \\
\hline (9) Química & $1.351,52$ & - & 9,9 & 11,6 & 62,9 & 15,6 \\
\hline (39) Saúde mercantil & $1.326,95$ & 0,6 & 17,3 & 39,5 & 11,0 & 30,0 \\
\hline (33) Serviços de informação & $1.058,77$ & - & 18,2 & 63,4 & 11,0 & 7,4 \\
\hline (19) Máquinas e equipamentos & 940,91 & 0,9 & 19,5 & 37,7 & 23,3 & 18,6 \\
\hline (38) Educação mercantil & 937,24 & 0,1 & 8,9 & 14,8 & 18,1 & 57,7 \\
\hline (7) Celulose e prod. de papel & 919,88 & 2,6 & 27,5 & 57,0 & 9,7 & 3,2 \\
\hline (36) Serviços de aloj. e alim. & 881,19 & 0,6 & 38,6 & 45,7 & 2,5 & 12,3 \\
\hline Demais setores & $5.554,55$ & 2,1 & 33,4 & 40,0 & 6,4 & 16,9 \\
\hline Total & $55.830,30$ & 1,8 & 25,0 & 34,3 & 11,3 & 26,8 \\
\hline
\end{tabular}

Tabela 2 - Distribuição da remuneração total por setor e percentual por grupo de anos de estudo, Paraná, 2006.

Fonte: Elaboração dos autores.

$\left({ }^{*}\right)$ valores correntes em $\mathrm{R} \$ 1.000 .000$. 
Os setores com maior dispêndio voltado à remuneração do fator trabalho foram: Com. e Serv. de manutenção (31); Administração Pública (42); Intermediação financeira e seguros (34); Educação Pública (41); e Outros serviços (40), de modo que os cinco juntos foram responsáveis por $48,1 \%$ do total da remuneração do trabalhadores no Estado, em 2006.

A razão do salário por trabalhador nos setores de atividade econômica, ou seja, o valor total do salário disposto na Tabela 2 dividido pelo número total de trabalhadores correspondentes em cada setor, dispostos na Tabela 1, impacta na média salarial anual. Contudo, por convenção, a média salarial anual foi convertida em média mensal, como na Tabela 3.

Notou-se que, a remuneração média do trabalhador é crescente à medida que aumenta o seu nível escolar. Para o grupo sem instrução escolar, a renda média aproximava-se de $R \$ 320,00$ mensais ${ }^{4}$. A renda média do trabalhador com escolaridade entre 1 a 8 anos de estudo cercava os $R \$$ 480,00 . Aos empregados classificados no ensino Médio, com escolaridade até 11 anos de estudo, a média salarial apresentou-se em torno de $\mathrm{R} \$ 780,00$ por mês, enquanto para o grupo com Graduação a média salarial foi de, aproximadamente, $\mathrm{R} \$ 1.450,00$, uma variação de $85 \%$ comparativamente ao grupo anterior. A maior média salarial voltou-se para o grupo de trabalhadores com escolaridade equivalente à Pós-Graduação, em torno de $\mathrm{R} \$ 2.650,00$, salário $82 \%$ maior relativamente ao dos trabalhadores com ensino Graduação e $240 \%$ maior em relação ao salário dos trabalhadores com ensino Médio (Tabela 3).

\begin{tabular}{|c|c|c|c|c|c|}
\hline \multirow{3}{*}{ SETOR } & \multicolumn{5}{|c|}{ REMUNERAÇÃO MEDIA MENSAL (*),POR ANOS DE ESTUDO } \\
\hline & SEM INSTRUÇÃO & FUNDAMENTAL & MEDIO & GRADUAÇÃO & POS \\
\hline & & $1 \mathrm{~A} 8$ & $9 \mathrm{~A} 11$ & 12 A 14 & $15 \leq$ \\
\hline (38) Educação Mercantil & 167,32 & 629,12 & 693,35 & 903,20 & $1.843,13$ \\
\hline (41) Educação Pública & 457,91 & 712,62 & 731,58 & $1.010,36$ & $1.692,61$ \\
\hline Média Total & 318,98 & 480,88 & 782,64 & $1.457,77$ & $2.654,44$ \\
\hline
\end{tabular}

Tabela 3 - Remuneração média mensal, por grupo de anos de estudo, Paraná, 2006.

Fonte: Elaboração dos autores.

$\left(^{\star}\right)$ Valores correntes em Reais.

Apesar de a escolaridade significar um indicador da média de anos de estudos, o que difere de qualificação, a média salarial encontrada para a economia paranaense em 2006 confirmou os resultados apontados pela literatura citada anteriormente, em que a renda tem relação positiva com o tempo escolar.

Os setores Educação Mercantil e Pública se apresentaram com média salarial muito próxima da média total de todos os setores, crescente à medida que se eleva o nível escolar. Cabe salientar que nesse segmento existe grande necessidade de mão de obra escolarizada e, também, qualificada. Assim, a elevada remuneração do fator trabalho funciona como atrativo para os funcionários melhor preparados, mantendo-os no setor. Realizada a descrição do perfil escolar da ocupação no Paraná em 2006, pode-se partir para a análise da geração de emprego e renda, detalhada na próxima seção.

\section{Geração de Emprego e Renda}

No Paraná, em 2006, o setor Educação, Pública e Mercantil empregou 4,9\% do total da ocupação no Estado e o dispêndio com a remuneração do fator trabalho movimentou $R \$ 4$ bilhões, como já discutido na seção anterior. Em paralelo, a educação influencia positivamente outros setores, fornecedores de insumos, no que se refere ao emprego e à renda. Para determinar a importância do setor Educação na geração, direta e indireta, de emprego e renda na economia paranaense, torna-se relevante mensurar seu potencial como ramo de atividade econômica específica.

A partir do aumento de uma unidade monetária na demanda final - composta por famílias, governo, investimentos e exportações - o que significaria o aumento no dispêndio de $\mathrm{R} \$ 1$ milhão realizado pelos seus componentes, foi mensurada a geração, direta e indireta, de novos postos de trabalho e renda na economia do Estado, no ano de 2006. Nas Tabelas 4 e 5 foram destacados os cinco setores com maior geração de emprego e renda, respectivamente, em cada nível de escolaridade.

De modo geral, em 2006, para a maioria dos setores, a criação de novos postos de trabalho seria maior para o grupo com Ensino Médio, com 23,4\% dos postos totais. Constatou-se baixa ocupação de pessoal sem instrução: para esse grupo estiveram voltados apenas $3,6 \%$ do total de empregos gerados. Já a geração de emprego para trabalhadores enquadrados no grupo Pósgraduação superaria aquela destinada aos trabalhadores graduados, com $9,4 \%$ contra $7,2 \%$, respectivamente, dos empregos gerados em todos os níveis de escolaridade. Tais constatações confirmam a tendência da busca de trabalhadores com maior qualificação formal e maior nível 
escolar, devido às exigências constantes no que tange à produtividade do fator trabalho, em razão da inovação tecnológica e da concorrência acirrada (Tabela 4).

No caso do aumento de uma unidade monetária na demanda final, a maior geração de emprego ocorreria nos seguintes setores: Outros serviços (40), com 101 novos postos; Metalurgia metais nãoferrosos (17), com 71 novos empregos; Extrativa mineral (2), com 61 postos de trabalho; Agricultura silv./expl.florl. (1), com 60; e Educação Pública (41), com 53 empregos gerados direta e indiretamente. Enquanto o setor Educação Mercantil (38), com a criação de empregos direta e indiretamente, ficaria em oitavo lugar, com 48 novos empregos (Tabela 4), tanto o setor Educação Pública quanto Educação Mercantil apresentam-se como sugestivos setores potenciais para políticas governamentais de geração de emprego.

Ao considerar os diversos níveis de escolaridade, os postos de trabalho gerados pelos setores (38) e (41) juntos, incorporando efeitos diretos e indiretos, seriam: dois empregos voltados ao grupo de trabalhadores sem instrução escolar, 17 empregos para os trabalhadores com ensino fundamental; 24 novos postos de trabalho àqueles com ensino médio e 57 empregos aos com ensino superior. Portanto, $57,0 \%$ dos empregos gerados nos dois setores estariam voltados aos profissionais graduados e pós-graduados, devido às características próprias desse segmento (Tabela 4).

Do contexto, pode-se inferir sobre a potencialidade econômica do setor Educação, ainda maior na Pública relativamente à Mercantil, na geração de empregos, pois o primeiro abrange maior número de instituições de ensino e funcionários, bem como despesas com insumos e outros. É importante considerar que os setores Educação Pública e Educação Mercantil provavelmente responderiam positivamente aos planos de política econômica de geração de emprego e renda devido à necessidade da ampliação decorrente do excesso de demanda, principalmente no que tange ao ensino superior.

\begin{tabular}{|c|c|c|c|c|c|c|}
\hline \multirow{3}{*}{ SETOR } & \multirow{3}{*}{$\begin{array}{c}\text { GE } \\
\text { TOTAL }\end{array}$} & \multicolumn{5}{|c|}{ GE POR ANOS DE ESTUDO } \\
\hline & & \multirow{2}{*}{$\begin{array}{c}\text { SEM } \\
\text { INSTRUÇÃO }\end{array}$} & \multirow{2}{*}{$\begin{array}{c}\begin{array}{c}\text { FUNDA- } \\
\text { MENTAL }\end{array} \\
1 \mathrm{~A} 8\end{array}$} & \multirow{2}{*}{$\begin{array}{r}\text { MEDIO } \\
9 \text { A } 11 \\
\end{array}$} & \multirow{2}{*}{$\frac{\text { GRADUAÇÃO }}{12 \text { A } 14}$} & \multirow{2}{*}{$\begin{array}{c}\text { POS } \\
15 \leq \\
\end{array}$} \\
\hline & & & & & & \\
\hline (40) Outros serviços & 101 & 6 & 61 & 27 & 3 & 3 \\
\hline (17) Metal. metais não-ferrosos & 71 & 2 & 29 & 34 & 4 & 1 \\
\hline (2) Extrativa mineral & 61 & 1 & 27 & 24 & 0 & 8 \\
\hline (1) Agricultura silv./expl.florl. & 60 & 11 & 39 & 8 & 1 & 0 \\
\hline (41) Educação Pública & 53 & 1 & 8 & 11 & 10 & 23 \\
\hline (5) Têxteis e Vestuário & 53 & 1 & 23 & 24 & 2 & 2 \\
\hline (36) Serviços de aloj. e alim. & 49 & 1 & 23 & 21 & 1 & 2 \\
\hline (38) Educação mercantil & 48 & 1 & 10 & 13 & 10 & 14 \\
\hline (31) Com. e Serv. de manut. & 47 & 1 & 16 & 24 & 4 & 2 \\
\hline (37) Serviços às empresas & 44 & 1 & 12 & 20 & 6 & 5 \\
\hline (30) Construção Civil & 43 & 2 & 29 & 9 & 1 & 1 \\
\hline (27) Outros eq. de transporte & 40 & 0 & 6 & 25 & 5 & 1 \\
\hline (39) Saúde mercantil & 38 & 1 & 10 & 17 & 5 & 5 \\
\hline (28) Móv. e prod. das ind. Div. & 36 & 0 & 19 & 14 & 1 & 1 \\
\hline (4) Alimentos, bebidas e fumo & 29 & 2 & 14 & 10 & 1 & 2 \\
\hline (8) Jornais, revistas, discos & 27 & 1 & 7 & 14 & 3 & 3 \\
\hline (32) Transp., armaz. e correio & 26 & 1 & 11 & 11 & 2 & 1 \\
\hline (33) Serviços de informação & 26 & 0 & 6 & 15 & 3 & 2 \\
\hline (6) Prod. de mad. exceto móv. & 25 & 2 & 14 & 7 & 1 & 1 \\
\hline (42) Administração Pública & 25 & 1 & 6 & 10 & 3 & 5 \\
\hline Demais setores & 287 & 10 & 107 & 114 & 22 & 28 \\
\hline Total por escolaridade & 1.189 & 43 & 476 & 452 & 86 & 112 \\
\hline
\end{tabular}

Tabela 4 - Geração de Emprego, por nível de escolaridade, Paraná, 2006.

Fonte: Elaboração dos autores.

Uma vez verificada a importância econômica dos setores na geração de emprego, faz-se necessário relacionar a criação de renda, que, por sua vez, deve ser interpretada como o volume de renda gerado, para atender à variação de uma unidade monetária na demanda final.

Estimou-se que a geração de emprego teria sido maior para os trabalhadores com Ensino Médio, os quais usufruiriam de $23,4 \%$ dos novos postos de trabalho criados na economia. Assim, a renda, ou remuneração do fator trabalho, também seria, em maior parte, $34,5 \%$, direcionada a esse grupo de trabalhadores. Em contrapartida, a menor parte da renda, 1,6\%, seria direcionada aos trabalhadores sem instrução escolar, no caso do aumento em uma unidade monetária na demanda final. Cabe observar que para os pós-graduados a renda gerada seria $27,2 \%$ do total na economia paranaense, para remunerar $9,4 \%$ dos novos trabalhadores (Tabela 5 ).

Os setores com alto potencial na geração de renda foram: Educação Pública (41); Administração Pública (42); Educação Mercantil (38); Outros serviços (40); e Serviços às empresas (37), de modo que os cinco setores juntos gerariam $25,7 \%$ da renda total estimada para economia paranaense em 2006. Torna-se interessante ressaltar que, como apresentado na Tabela 4, os setores 37, 38, 40 e 41 estavam entre os dez maiores geradores de emprego. Desse modo, os respectivos setores seriam 
aqueles que, potencialmente, justificariam plenamente implantações de políticas de geração de emprego e renda.

\begin{tabular}{|c|c|c|c|c|c|c|}
\hline \multirow{3}{*}{ SETOR } & \multirow{3}{*}{$\begin{array}{c}\text { GR } \\
\text { TOTAL } \\
\left(^{*}\right)\end{array}$} & \multicolumn{5}{|c|}{ GR POR ANOS DE ESTUDO $\left(^{*}\right)$} \\
\hline & & $\begin{array}{c}\text { SEM } \\
\text { INSTRU- }\end{array}$ & $\begin{array}{l}\text { FUNDA- } \\
\text { MENTAL }\end{array}$ & MEDIO & $\begin{array}{c}\text { GRADU- } \\
\text { ACÃO }\end{array}$ & POS \\
\hline & & ÇÃO & $1 \mathrm{~A} 8$ & 9 A 11 & 12 A 14 & $15 \leq$ \\
\hline (41) Educação Pública & 751,37 & 3,62 & 56,57 & 94,00 & 124,41 & 467,71 \\
\hline (42) Administração Pública & 609,75 & 5,94 & 67,91 & 179,55 & 63,68 & 288,75 \\
\hline (38) Educação mercantil & 602,55 & 1,53 & 66,18 & 108,18 & 104,62 & 319,72 \\
\hline (40) Outros serviços & 510,48 & 21,25 & 239,03 & 154,88 & 37,34 & 50,62 \\
\hline (37) Serviços às empresas & 384,17 & 3,18 & 68,04 & 151,08 & 67,27 & 93,31 \\
\hline (39) Saúde mercantil & 383,36 & 2,87 & 71,63 & 152,49 & 43,31 & 107,68 \\
\hline (31) Com. e Serv. de manut. & 372,07 & 3,41 & 100,48 & 180,66 & 38,08 & 47,66 \\
\hline (27) Outros eq. de transporte & 366,66 & 0,77 & 29,58 & 251,18 & 31,37 & 16,51 \\
\hline (23) Mat. elétron.eq.de com. & 342,83 & 0,99 & 20,81 & 74,92 & 88,18 & 152,08 \\
\hline (34) Interm. finan. e seguros & 336,74 & 2,87 & 18,60 & 68,19 & 56,25 & 190,16 \\
\hline (32) Transp., armaz., correio & 290,54 & 4,47 & 113,48 & 107,78 & 24,92 & 35,66 \\
\hline (2) Extrativa mineral & 289,37 & 2,90 & 98,13 & 104,49 & 6,28 & 77,03 \\
\hline (8) Jornais, revistas, discos & 277,56 & 3,71 & 56,45 & 115,48 & 45,89 & 55,67 \\
\hline (19) Máquinas e equip. & 263,45 & 2,75 & 53,58 & 98,02 & 53,18 & 55,45 \\
\hline (15) Prod. Min. não-metálicos & 262,29 & 12,45 & 104,19 & 88,17 & 37,06 & 17,60 \\
\hline (7) Celulose e prod. de papel & 256,24 & 7,78 & 74,90 & 125,28 & 25,87 & 21,91 \\
\hline (5) Têxteis e Vestuário & 255,19 & 2,01 & 95,41 & 106,15 & 13,27 & 35,00 \\
\hline (6) Prod. de mad. exc. móv. & 247,35 & 11,41 & 111,66 & 84,65 & 14,29 & 22,05 \\
\hline (33) Serviços de informação & 246,76 & 0,84 & 48,40 & 138,85 & 28,59 & 29,68 \\
\hline (36) Serviços de aloj. e alim. & 246,54 & 2,84 & 90,62 & 106,22 & 9,41 & 36,30 \\
\hline Demais setores & $4.220,63$ & 92,32 & $1.209,80$ & $1.480,83$ & 396,24 & $1.006,51$ \\
\hline Total por escolaridade & $11.515,91$ & 189,92 & $2.795,47$ & $3.971,03$ & $1.309,51$ & $3.127,05$ \\
\hline
\end{tabular}

No caso do setor Educação, além da capacidade de criar de novos postos de trabalho e renda, cuja repercussão seria a injeção de uma massa de salários na economia, propiciada pelo consumo futuro, possui a capacidade de promover benefícios individuais e também sociais - no que concerne à formação de uma sociedade mais democrática, menos desigual, com maior liberdade para fazer escolhas e com mais oportunidades. Em suma, constatou-se que o setor Educação se sobressaiu perante os demais setores econômicos na capacidade de influir no âmbito socioeconômico, no curto e no longo prazos.

\section{Considerações finais}

No âmbito dos estudos focados em demonstrar os diversos papéis da educação, esta pesquisa se propôs a determinar qual a importância econômica dos setores Educação Pública e Educação Mercantil no Paraná, em 2006. De modo específico, objetivou-se verificar o perfil educacional das pessoas ocupadas em contraponto à renda; determinar a geração de emprego e renda em sete grupos classificados de acordo com o perfil educacional da mão de obra, em todos os setores da economia, com destaque para o setor Educação; e comparar a importância econômica do setor Educação, Pública e Mercantil, frente aos demais setores.

A relação escolaridade e renda, ou remuneração pelo trabalho, apresentou-se crescente à medida que se eleva o nível escolar do trabalhador. O salário mensal médio do pessoal com escolaridade entre 1 a 4 anos apresentou-se maior em 31,8\% relativamente ao salário médio do pessoal sem instrução escolar. Com relação à média salarial dos indivíduos com ensino Fundamental em relação aos com ensino Médio completo, esta foi maior, cerca de, 83,5\%, comparada àquela. $\mathrm{A}$ variação da média salarial entre o pessoal com nível Graduação e aqueles com nível Médio atingiu $85 \%$. A maior média salarial voltou-se ao grupo com trabalhadores com escolaridade equivalente à Pós-Graduação, em torno de $\mathrm{R} \$ 2.650,00$ - salário $82 \%$ maior na comparação com os trabalhadores possuidores da Graduação e $240 \%$ maior com relação ao salário dos trabalhadores apenas com ensino Médio.

Dentre os setores, os que mais demandaram mão de obra melhor escolarizada, ressaltaram-se: Eletrodomésticos; Fabricação de veículos automotores; Intermediação financeira e seguros; Educação Pública; Materiais eletrônicos e equipamentos de comunicação; Serviços de informação; Educação Mercantil; Máquinas para escritório e para informática; Administração Pública; e Outros equipamentos de transporte. Dentre estes o setor que mais abrigou trabalhadores com mais de 
quinze anos de estudo foi Educação Pública com, aproximadamente, $21 \%$ do total de pessoas do grupo. Em valor absoluto, esse percentual representa 98,5 mil empregados.

No entanto, foi a geração de emprego e renda que apresentou a pujança econômica do setor Educação. Para o aumento de uma unidade monetária na demanda final, a maior geração de emprego ocorreria nos setores: Outros serviços; Metal. metais não-ferrosos; Extrativa mineral; Agricultura silvicultura e exploração florestal; e Educação Pública. O setor Educação Mercantil ficou em oitavo lugar, dentre os 42 setores.

Quanto à geração de renda, a Educação Pública, a Administração Pública e a Educação Mercantil foram os setores de maior destaque na economia paranaense em 2006. Logo, tanto o setor Educação Pública quanto Educação Mercantil apresentaram-se como sugestivos setores potenciais para políticas governamentais de geração de emprego e renda. Interessante ressaltar que, juntos, esses setores gerariam $8,5 \%$ do total de empregos e 9,7\% do total da renda do Paraná, como resultado do aumento de um milhão de reais em suas demandas finais.

Pode-se concluir que, além das externalidades sociais geradas no longo prazo, os setores Educação Pública e Mercantil impactaram no curto prazo, de forma veemente, a economia local e influenciaram a renda e o emprego de vários setores interconectados.

Assim, considerando os importantes papéis da Educação, com grande importância na determinação do rendimento dos trabalhadores paranaenses, torna-se clara a necessidade de políticas públicas eficientes. Ampliar as oportunidades de educação formal e treinamento profissional com maior oferta de escolas públicas e cursos técnicos profissionalizantes gratuitos - e mesmo subsídios às instituições de ensino para bolsas de estudo - são pertinentes investimentos porque têm retorno socioeconômico.

Saliente-se que a continuidade da atual pesquisa poderia, de forma muito interessante, investigar e analisar economicamente o setor Educação por maior período. No entanto, há muitos aspectos a serem explorados dentro do tema enfocado nesta pesquisa, o que demonstra a necessidade de estudos futuros. Tal oportunidade certamente se constituiria como um complemento à altura das idéias e conclusões já expostas ao longo da presente pesquisa, a fim de explorar as diversas implicações de longo prazo do setor Educação para o desenvolvimento econômico do Paraná.

\title{
Notas
}

\begin{abstract}
Entende-se como escolaridade a aprendizagem na educação formal, referente ao ensino básico e superior, medida por anos de estudo. A escolarização pode ser interpretada como Proxy da qualificação da mão de obra, porém, deve-se ressaltar que são dois elementos diferentes.

${ }_{2}^{2} \mathrm{Na}$ economia, considera-se como curto prazo o período em que os elementos de oferta estão constantes e o choque impactante vem pelas alterações na demanda. O oposto é definido como longo prazo.

${ }^{3} \mathrm{~A}$ saber: (1)Agricultura, silvicultura, exploração florestal; (2)Extrativa mineral; (3)Pecuária e pesca; (4)Alimentos, bebidas e fumo; (5)Têxteis e Vestuário; (6)Produtos de madeira - exclusive móveis; (7)Celulose e produtos de papel; (8)Jornais, revistas, discos; (9)Química; (10)Produtos farmacêuticos; (11)Perfumaria, higiene e limpeza; (12)Tintas, vernizes, esmaltes e lacas; (13)Produtos e preparados químicos diversos; (14)Artigos de borracha e plástico; (15)Produtos de minerais não-metálicos; (16)Fabricação de aço e derivados; (17)Metalurgia de metais não-ferrosos; (18)Produtos de metal - exclusive máquinas e equipamentos; (19)Máquinas e equipamentos, inclusive manutenção e reparos; (20)Eletrodomésticos; (21)Máquinas para escritório e equipamentos de informática;(22)Máquinas, aparelhos e materiais elétricos; (23)Material eletrônico e equipamentos de comunicações; (24)Aparelhos/instrumentos médico-hospitalar, medida e óptico; (25)Fabricação e montagem de veículos automotores; (26)Peças e acessórios para veículos automotores; (27)Outros equipamentos de transporte; (28)Móveis e produtos das indústrias diversas; (29)Eletricidade e gás, água, esgoto e limpeza urbana; (30)Construção; (31)Comércio e Serviços de manutenção e reparação; (32)Transporte, armazenagem e correio; (33)Serviços de informação; (34)Intermediação financeira e seguros; (35)Serviços imobiliários e aluguel; (36)Serviços de alojamento e alimentação; (37)Serviços prestados às empresas; (38)Educação mercantil; (39)Saúde mercantil; (40)Outros serviços; (41)Educação Pública; (42)Administração Pública.

${ }^{4}$ A Lei $n^{\circ}$ 11.321, vigente a partir de 7 de julho de 2006, regulamentava um salário mínimo no valor de $R \$ 350,00$, dantes $R \$$ 300,00 .
\end{abstract}

\section{Referências}

BARROS, R. P.; CAMARGO, J. M.; MENDONÇA, R. A estrutura do desemprego no Brasil. Rio de Janeiro: IPEA, 1997. (Texto para Discussão, 478).

BARROS, R. P.; MENDONÇA, R. Investimentos em educação e desenvolvimento econômico. Rio de Janeiro: IPEA, 1997. (Texto para Discussão, 525). 
BRASIL. Lei no 9.394, de 20 de dezembro de 1996. Estabelece as diretrizes e bases da educação nacional. Diário Oficial [da] República Federativa do Brasil, Brasília, v. 134, n. 248, seção 1, p. 27834-27841. 23 dez. 1996

DUCH, N.; GARCÍA, J.; PARELLADA, M. The economic impact of the Spanish public university system: an analysis for the period 1998-2004. Barcelona, 2008. Document de Treball 2008/9 Institut d’Economia de Barcelona.

FERREIRA, S. G.; VELOSO, F. A escassez da educação. In: GIAMBIAGI, F; et al. Economia brasileira contemporânea (1945-2004). Rio de Janeiro: Elsevier, 2005.

HANUSHEK, E. A.; WOESSMANN, L. The role of cognitive skills in economic development. Journal of Economic Literature, Nashville, v. 46, n. 3, p. 607-668, 2008.

IBGE. Pesquisa nacional por amostra de domicílios 2006. Rio de Janeiro, 2006. 1 CD-ROM.

CONCLA - Comissão Nacional de Classificação, Rio de Janeiro, 2010. Disponível em: <http://www.ibge.gov.br/concla/cl_download.php?sl=4>. Acesso em: 15 nov. 2010.

KURESKI, R. Produto interno bruto: emprego e renda do macrossetor da construção civil paranaense. 2006. Texto não publicado.

LANGONI, C. G. A economia da transformação. Rio de Janeiro: Biblioteca do Exército, 1976. 213 p. MIERNYK, W. H. Elementos de análise do insumo-produto. São Paulo: Atlas, 1975. 164 p.

MILLER, R. E.; BLAIR, P. D. Input-output analysis: foundations and extensions. New York: Cambridge University Press, 2009. 750 p.

RAMOS, L.; MENDONÇA, R. Pobreza e desigualdade de renda no Brasil. In: GIAMBIAGI, F. et al. Economia brasileira contemporânea (1945-2004). Rio de Janeiro: Elsevier, 2005.

ROLIM, C.; KURESKI, R. Impacto econômico de curto prazo das universidades estaduais paranaenses - 2004. Revista Paranaense de Desenvolvimento, Curitiba, v. 112, p.111-130, jan./jun. 2007.

ZAIST, J. V.; NAKABASHI, L.; SALVATO, M. Retornos privados da escolaridade no Paraná. Revista Economia, Brasília, v. 11, p. 175-198, jan./abr. 2010. 